\title{
Proteína do soro de leite: Aproveitamento e aplicações na produção de embalagem biodegradável
}

\section{Whey protein: use and application in the production of biodegradable packaging}

\author{
Regiane Ribeiro-Santos ${ }^{l}$, André Luis Rodrigues Souza ${ }^{2}$, Felipe Machado Trombete ${ }^{l}$, Nathália Ramos de Melo ${ }^{4}$
}

Resumo: O soro de leite é um resíduo originado da indústria de laticínios, seu descarte é preocupante, considerando o apelo em relação à preservação do meio ambiente. Além disso, as proteínas do soro de leite são desperdiçadas como resíduo podendo, essas, serem utilizadas em diversas aplicações alimentícias devido aos seus e benefícios para a saúde, sendo uma excelente fonte de aminoácidos indispensáveis. $\mathrm{O}$ aproveitamento dessas proteínas é sugerido no enriquecimento ou desenvolvimento de novos produtos, inserindo-as na alimentação como uma forma nutritiva e sensorialmente aceita, além de uma alternativa para o gerenciamento do resíduo. Outra forma de aproveitamento dessas proteínas é na elaboração de embalagens de alimentos como os filmes e revestimentos comestíveis. Esses apresentam vantagens como: extensão da validade comercial e melhoria na qualidade nutricional dos alimentos, além disso, atuam na redução às embalagens sintéticas. Desta forma, essa revisão teve como objetivo elucidar as vantagens do aproveitamento do soro lácteo, bem como de suas proteínas, na elaboração ou enriquecimento de alimentos e principalmente na produção de embalagens biodegradáveis. O trabalho foi realizado por meio de uma abordagem qualitativa utilizando consultas a bases de dados nacionais e internacionais. $\mathrm{O}$ reaproveitando do soro de leite na elaboração de produtos como: bebidas lácteas, pães, e biscoitos é desejável uma vez os alimentos são nutricionalmente enriquecidos e inclui uma série de benefícios à saúde. E na produção de embalagens as proteínas apresentam vantagens como melhorias de qualidade nutricional e garantia de segurança do alimento, além do fato de poderem ser comestíveis e biodegradáveis.

Palavras-chaves: Filmes, revestimentos, embalagens de alimentos, concentrado proteico, isolado protéico.

\begin{abstract}
The whey is a residue of the dairy industry. The waste of whey is worrying appeal the regarding the preservation of the environment. Furthermore, the whey proteins are wasted as a residuum and may, however, be used in various food applications due to their health benefits, being an excellent source of essential amino acids. The use of these proteins is suggested mainly enrichment or developing new products, entering it in food as a form nutritious and sensory supports, and a viable alternative for the management of this waste. Another way to use the whey proteins is the preparation of food packaging, such as films and edible coating. The film and coating of whey protein have some advantage such as to extend shelf life and improve the nutritional quality of the food, furthermore, they reduce the use of synthetic packaging. This review aimed to report the advantages of the use of whey as well as their protein, in the development or enrichment of the food and production of biodegradable packaging. This study was conducted through a qualitative approach based on consultations with national and international databases. The reutilization of whey in the development of products such as milk drinks, breads, and cookies, it is desirable, once foods are nutritionally enriched and include a number of health benefits. And, in the production of packaging, the proteins have advantages as nutritional quality improvements and food safety assurance, beyond the fact that the packagings are biodegradable and it may be edible.
\end{abstract}

Key words: Films, coating, food packaging, protein concentrate, protein isolate

\footnotetext{
* Autor para correspondência

Recebido para publicação em 21/11/2014; aprovado em 15/09/2015

${ }^{1}$ Doutoranda do Programa de Pós-graduação em Ciência e Tecnologia de Alimentos, Universidade Federal Rural do Rio de Janeiro - UFRRJ, Seropédica - RJ, E-mail: ribeirorsantos@gmail.com

${ }^{2}$ Doutorando do Programa de Pós-graduação em Ciência dos Alimentos, Universidade Federal do Rio de Janeiro - UFRJ, E-mail: rodrigues_andreluis@yahoo.com.br

${ }^{3}$ Doutorando do Programa de Pós-graduação em Ciência e Tecnologia de Alimentos, Universidade Federal Rural do Rio de Janeiro - UFRRJ, E-mail: felipetrombete@gmail.com

${ }^{4}$ D. Sc Professora da Universidade Federal Fluminense e do Programa de Pós-graduação em Ciência e Tecnologia de Alimentos da Universidade Federal Rural do Rio de Janeiro, E-mail: nathaliarm1@gmail.com
} 


\section{INTRODUÇÃO}

Segundo a Organização Mundial de Saúde (OMS, 2009), o leite e seus derivados constituem uma fonte rica e conveniente de nutrientes para a população de muitos países e, o volume que movimenta o comércio internacional é significativo.

A produção de leite no Brasil entre 2010 e 2011 foi de 32,1 bilhões de litros (IBGE, 2013). Cerca de 25\% de leite brasileiro é destinado a produção de queijos, segundo as pesquisas realizadas pela United States Department of Agriculture (USDA) em 2010. Dentre os derivados lácteos comercializados mundialmente, os queijos merecem destaque visto que representam cerca de $40 \%$ do valor total das exportações de lácteos (SIQUEIRA et al., 2010).

Durante a fabricação de queijo é obtido o soro de leite, esse é constituído de uma mistura de proteína, lactose, sais minerais, e vitaminas (ANDRADE; MARTINS, 2002).

As proteínas presentes no soro de leite apresentam propriedades tecnológicas interessantes como: solubilidade (PELEGRINE; GASPARETTO, 2003), emulsificação (PEREZ GAGO; KROCHTA, 2000; SINHA et al., 2007), gelatinização (NGARIZE et al., 2005) e capacidade de reter água (VIDIGAL et al., 2012). Além disso, têm função antimicrobiana e antioxidante (MARSHALL 2004; ARTIMONTE 2009).

Devido a sua rica constituição nutricional, o soro de leite pode acarretar graves problemas quando descartado de forma incorreta no ambiente. Queiroz et al. (2011) estimaram a produção de queijo e o descarte do soro, oriundo de uma indústria de laticínios de Minas Gerais durante um período de 3 anos (2008-2010), eles concluíram que houve um aumento na produção de queijo muçarela, e em 2010, as quantidades de leite processado, soro de leite e produção de queijo foi de 261.549 L, 235.394 L e $26.154 \mathrm{~kg}$, respectivamente.

Portanto, diversos trabalhos de pesquisa têm sido desenvolvidos visando novas opções para a utilização deste resíduo para consumo humano e, ao mesmo tempo, descaracterizando o soro como um agente de poluição ambiental (SILVA, 2004; CIABOTTI et al.; 2009; SILVA et al., 2011; ROCHA, 2012).

Outra alternativa para o aproveitamento do soro de leite é a extração e aplicação das soroproteínas na formação de filmes e revestimentos comestíveis, tais como embalagens de alimentos.

As embalagens convencionais apresentam camadas de diferentes materiais sintéticos de difícil degradação no ambiente, portanto, há um interesse crescente no desenvolvimento de polímeros biodegradáveis, denominados biopolímeros. Este tipo de embalagem pode ser eliminada de maneira economicamente e ecologicamente aceitável após a utilização (HONG; KROTCHA, 2006). Além disso, elas podem ser incorporadas de diversos aditivos que melhoram a qualidade nutricional e a segurança do alimento.

Desta maneira, esta revisão teve como objetivo apresentar as vantagens do aproveitamento do soro de leite, bem como de suas proteínas, na elaboração ou enriquecimento de alimentos e na produção de embalagens biodegradáveis.

\section{METODOLOGIA}

O presente trabalho constitui uma pesquisa de abordagem qualitativa com foco em descrever sobre o aproveitamento e aplicação das proteínas do soro de leite na produção de embalagens biodegradáveis. Foram realizadas pesquisas por meio de consultas a bases de dados nacionais e internacionais, sendo livros, periódicos, informações governamentais, revistas, informativos, trabalhos de dissertação e teses publicados.

\section{REVISÃO BIBLIOGRÁFICA}

\section{Soro de leite: Resíduo agroindustrial}

O soro de leite, também conhecido como soro lácteo, é um líquido residual obtido a partir da coagulação do leite, destinado à fabricação de queijos e caseína (BRASIL, 1996). Representa a porção aquosa do leite de onde são extraídas as proteínas do soro (ANDRADE; MARTINS, 2002; EGITO et al., 2007).

O soro representa cerca de 85 a $90 \%$ do volume total de leite que entra no processo de fabricação do queijo, variando conforme o tipo de queijo processado, e contém cerca de 50\% $\mathrm{m} / \mathrm{m}$ dos nutrientes do leite (ALMEIDA et al., 2001), tais como proteínas, lactose, minerais e vitaminas (ANDRADE; MARTINS, 2002; MAGANHA, 2006). A composição básica de um soro de leite obtido na produção de queijo "tipo coalho" é apresentada no Quadro 1.

Quadro 1-Composição físico-química do soro de leite proveniente do queijo "Tipo Coalho"

\begin{tabular}{|l|c|}
\hline \multicolumn{1}{|c|}{ Componentes Físico-Químicos } & $\begin{array}{c}\text { Resultado Médio } \\
\text { (Desvio Padrão) }\end{array}$ \\
\hline $\mathrm{pH}$ & $6,34 \pm 0,54$ \\
\hline Acidez em graus Dornic $\left({ }^{\circ} \mathrm{D}\right)$ & $11,00 \pm 1,16$ \\
\hline Gordura $(\%)$ & $0,33 \pm 0,06$ \\
\hline Lactose $(\%)$ & $4,25 \pm 0,05$ \\
\hline Extrato seco total $(\%)$ & $6,43 \pm 0,08$ \\
\hline Sais minerais $(\%)$ & $0,60 \pm 0,01$ \\
\hline Proteína $(\%)$ & $1,25 \pm 0,06$ \\
\hline Extrato seco desengordurado $(\%)$ & $6,10 \pm 0,11$ \\
\hline Umidade $(\%)$ & $93,57 \pm 0,08$ \\
\hline
\end{tabular}

Fonte: Barbosa et al. (2010)

O soro lácteo possui sabor ligeiramente ácido ou doce, dependendo do tipo de queijo que se pretende obter. O soro doce é o tipo predominante de soro. É proveniente da coagulação enzimática (BRASIL, 2013), que acontece pela hidrólise da caseína por enzimas proteolíticas de origem animal como, por exemplo, a renina conhecida pelo nome popular de coalho (EGITO et al., 2007). Enquanto que, o soro ácido é oriundo da coagulação do leite produzida principalmente por acidificação (BRASIL, 2013), podendo também ser proveniente da coagulação ácida do leite após a transformação da lactose em ácido láctico por ação das bactérias láticas (EGITO et al., 2007).

O soro de leite é considerado um efluente residual e, devido ao seu alto teor de matéria orgânica, pode acarretar graves problemas ambientais, afetando significativamente a qualidade dos efluentes das indústrias que não estão adaptadas para sua recuperação. Um litro de leite integral 
equivale aproximadamente a uma demanda biológica de oxigênio (DBO) de $110.000 \mathrm{mg}$ L-1 e a uma demanda química de oxigênio (DQO) de $210.000 \quad \mathrm{mg} \quad$ L-1 (MAGANHA, 2006).

\section{Proteínas do soro de leite}

O soro lácteo contém de 4 a $6 \mathrm{~g}$ de proteínas por litro (PELEGRINE; CARRASQUEIRA, 2008). As proteínas do soro estão em torno de 15 a $20 \%(\mathrm{~m} / \mathrm{m})$ de proteína total contidas no leite e este valor está relacionado com a produção de soro (ácido ou doce) e tipo de queijo (MAGANHA, 2006).

Quadro 2- Principais proteínas presentes no soro de leite bovino

\begin{tabular}{|c|c|c|}
\hline Componentes do soro de leite & $\%(\mathrm{~m} / \mathrm{m})$ de proteína do soro de leite & Benefícios* \\
\hline$\beta-$ lactoglobulina & $50-55$ & Fonte de aminoácidos indispensáveis \\
\hline$\alpha-$ lactalbumina & $20-25$ & Fonte de aminoácidos de cadeia ramificada \\
\hline Soroalbumina (BSA) & $5-10$ & Fonte de aminoácidos indispensáveis \\
\hline Imunoglobulina & $10-15$ & Imunomoduladoras \\
\hline Lactoferrina & $1-2$ & Antioxidante, antibacteriana, antiviral, antifúngica \\
\hline Lactoperoxidase & 0,5 & Antibacteriana \\
\hline
\end{tabular}

* Depende do volume de consumo

Fonte: Marshall (2004) adaptado

Os produtos comerciais de proteína de soro de leite variam de $35 \%$ a $97 \%$ de conteúdo proteico (base seca). Níveis de proteína de $35-90 \%$ referem-se como os concentrados de proteína de soro de leite (CPS) ou WPC (Whey Protein Concentrates) e níveis maiores que 90\% são designados por isolados de proteína de soro de leite (IPS) ou WPI (Whey Protein Isolate) (HONG; KROCHTA, 2006).

As composições dos produtos de IPS e CPS também diferem nos níveis dos seus vários constituintes, especialmente lactose como apresentado no Quadro 3.

Quadro 3- Composição química do isolado proteico de soro (IPS) e concentrado proteico de soro (CPS) de proteínas de soro de leite em pó.

\begin{tabular}{|c|c|c|}
\hline \multirow{2}{*}{ Composição } & \multicolumn{2}{|c|}{$\begin{array}{c}\text { Proteína do soro de leite } \\
\text { (Média } \pm \text { Desvio Padrão) }\end{array}$} \\
\cline { 2 - 3 } & IPS & CPS \\
\hline Proteína $(\%, \mathrm{~m} / \mathrm{m})$ & $92,0 \pm 1,0$ & $82,0 \pm 2,0$ \\
\hline Lactose $(\%, \mathrm{~m} / \mathrm{m})$ & $1,0 \pm 1,0$ & $6,0 \pm 4,0$ \\
\hline Lipídeos $(\%, \mathrm{~m} / \mathrm{m})$ & $1,0 \pm 0,1$ & $1,6 \pm 0,1$ \\
\hline Cinza $(\%, \mathrm{~m} / \mathrm{m})$ & $2,0 \pm 0,1$ & $4,4 \pm 0,1$ \\
\hline Umidade $(\%, \mathrm{~m} / \mathrm{m})$ & $3,0 \pm 0,1$ & $3,3 \pm 0,2$ \\
\hline Cálcio $(\mathrm{mg} / 100 \mathrm{~g})$ & $389,1 \pm 12,2$ & $200,0 \pm 11,0$ \\
\hline Sódio $(\mathrm{mg} / 100 \mathrm{~g})$ & $100,1 \pm 7,3$ & $400,1 \pm 17,9$ \\
\hline Potássio $(\mathrm{mg} / 100 \mathrm{~g})$ & $31,1 \pm 1,3$ & $50,2 \pm 2,4$ \\
\hline
\end{tabular}

Fonte: Ramos et al. (2013)

Tanto o IPS quanto o CPS constituem uma excelente alternativa para o enriquecimento de alimentos e produção de filmes e revestimentos comestíveis. A lactose, presente em maior quantidade no CPS, age como um plastificante (HONG; KROCHTA, 2006), ingrediente essencial para produção de filmes e revestimentos (YOSHIDA; ANTUNES, 2009).

\section{Elaboração de alimentos a base de proteína do soro de leite}

Uma alternativa para minimizar o impacto ambiental e aproveitar as propriedades nutritivas do soro de leite é
As proteínas do soro de leite incluem: $\alpha$ - lactalbumina, $\beta$ - lactoglobulina, lactoferina, lactoperoxidases, lisozima junto com outros componentes menores (SGARBIERI, 2004). São responsáveis por diversos benefícios (BOUTIN et al., 2007) como os citados no Quadro 2. A $\alpha$ - lactalbumina e a $\beta$ - lactoglobulina correspondem a maior parte do total de proteínas.

Os benefícios causados pelas proteínas dependem da quantidade consumida através dos alimentos lácteos. Quando ingerido um litro de leite bovino, por exemplo, são consumidos, aproximadamente: $3,2 \mathrm{~g}$ de $\beta$ - lactoglobulina, $1,2 \mathrm{~g}$ de $\alpha$ - lactalbumina, $0,1 \mathrm{~g}$ de lactoferina, $0,4 \mathrm{~g}$ de soroalbumina e $0,7 \mathrm{~g}$ de imunoglobulina (SGABIERI, 2004). utilizando-o na produção de novos produtos alimentícios ou agregando valor aos já existentes.

Santos et al. (2006) ressaltaram que $50 \%$ da produção mundial de soro é processada e transformada em vários produtos alimentares, sendo que deste total, quase a metade é usada diretamente na forma líquida.

As proteínas de soro apresentam a maioria dos aminoácidos indispensáveis em excesso às recomendações diárias para saúde humana, recomendados pela FAO (Food and Agriculture Organization), exceto pelos aminoácidos aromáticos (fenilalanina e tirosina) que não estão presentes em excesso, mas atendem às recomendações para todas as idades. Apresentam também elevadas concentrações dos aminoácidos triptofano, cisteína, leucina, isoleucina e lisina (SGABIERI, 2004; SINHA et al., 2007).

Roman e Sgarbieri (2007) fizeram um estudo sobre o perfil de aminoácidos do IPS com base no perfil recomendado pela FAO, o resultado pode ser visto no Quadro 4.

As proteínas do soro de leite apresentam diversas propriedades funcionais, como solubilidade e capacidade de emulsificação (PAGNO et al., 2009), podendo ser usadas para estabilizar emulsão óleo e água ou para formação de géis após aquecimento (BOUTIN et al., 2007).

Ingredientes de proteína do soro de leite são usados para uma variedade de aplicações funcionais na indústria de alimentos. Algumas aplicações estão apresentadas no Quadro 5.

Sinha et al. (2007) hidrolisou enzimaticamente o CPS e o utilizou como ingrediente para obtenção de uma mistura para achocolatado. O CPS após hidrólise tornou alguns aminoácidos mais disponível, tais como: ácido glutâmico, serina, glicina, treonina, metionina e tirosina. A bebida formulada não apresentou diferença sensorial quando comparada ao achocolatado comercial. 
Quadro 4-Perfil de aminoácidos do IPS com base no padrão de referência da FAO

\begin{tabular}{|l|c|c|c|}
\hline $\begin{array}{l}\text { AA indispensáveis } \\
(\mathrm{g} / 100 \mathrm{~g} \text { de proteína })\end{array}$ & $\begin{array}{c}\text { Padrão FAO } \\
(2-5 \text { anos })\end{array}$ & $\begin{array}{c}\text { Padrão FAO } \\
\text { Adultos }\end{array}$ & IPS \\
\hline Treonina & 3,4 & 0,9 & 4,7 \\
\hline Metionina + Cistina & 2,5 & 1,7 & 8,0 \\
\hline Valina & 3,5 & 1,3 & 4,8 \\
\hline Leucina & 6,6 & 12,8 & 12,8 \\
\hline Isoleucina & 2,8 & 6,3 & 5,0 \\
\hline Fenilalanina + Tirosina & 6,3 & 5,8 & 6,8 \\
\hline Lisina & 5,8 & 1,6 & 10,2 \\
\hline Histidina & 1,9 & 0,5 & 2,0 \\
\hline Triptofano & 1,1 & & \\
\hline
\end{tabular}

IPS- isolado proteico de soro; AA- aminoácidos; FAO- Food and Agriculture Organization (1990)

Fonte: Roman e Sgarbieri (2007)

Quadro 5- Aplicação do soro de leite na indústria de alimentos

\begin{tabular}{|c|c|}
\hline Aplicação & Referências \\
\hline Bebidas Lácteas & Caldeira et al. (2010); \\
\hline Filmes comestíveis & Yashida;Antunes (2009); Ramos et al. (2013) \\
\hline Biscoitos, bolo e tofu & Zaveze et al. (2010); Guimarães (2011), Ciabotti et al., 2009 \\
\hline $\begin{array}{c}\text { Enriquecimento de produtos (cereal matinal, } \\
\text { iogurte, doces de leite, sorvetes, pão, } \\
\text { extrusados, bebidas) }\end{array}$ & $\begin{array}{c}\text { Zambrano et al. (2012);. Silva et al. (2011); Silva et al. (2004); Rocha et al. (2012), Silva; } \\
\text { Bolini (2006); Valduga et al. (2006), Embrapa (2011); Sinha et al. (2007). }\end{array}$ \\
\hline Ricota & Egito et al. (2007) \\
\hline Meio de fermentação para bactérias e fungos & Diniz et al. (2012); Barbosa et al. (2010) \\
\hline
\end{tabular}

Ciabotti et al. (2009) aproveitaram o resíduo ao associá-lo ao extrato de soja como uma alternativa de enriquecimento das proteínas da soja por serem deficientes em aminoácidos sulfurados como metionina e cisteína, uma vez que o soro de leite os possui em altas concentrações.

Diniz et al. (2012) usaram o soro de leite como fonte de carbono para produção de enzimas. Enquanto, Pelegrine e Carrasqueira (2008), associaram ao soro ácido à função de realçador de sabor de molhos cremosos para saladas, retentor de água, emulsificante e fonte de cálcio, e ao soro doce associaram diversas aplicações em produtos de panificação, salgadinhos, sorvetes e sobremesas lácteas.

Pesquisas na Embrapa (2012) investigaram o uso do soro como um ingrediente funcional capaz de atuar como coadjuvante em tratamentos para hipertensão e problemas cardiovasculares. Da proteína obtêm-se os peptídeos, moléculas de aminoácidos indispensáveis para o bom funcionamento do organismo e que possuem efeito antihipertensivo. A ideia é concentrar os peptídeos bioativos na forma de pó para utilizá-lo como ingrediente na formulação de alimentos funcionais. Os alimentos funcionais são responsáveis por efeitos metabólicos benéficos à saúde e bem-estar e podem atuar como coadjuvantes na prevenção e tratamento de doenças.

Outro trabalho também desenvolvido pela Embrapa (2011) propõe a adição de IPS na farinha de arroz branco polido que dará origem aos snacks. Embora o arroz forneça todos os recursos para a produção de extrusados expandidos, seu valor nutricional é baixo, portanto o uso de IPS enriquece o produto e não afeta, negativamente, a expansão.

\section{Embalagens proteicas para alimentos}

O interesse de desenvolver embalagens biodegradáveis e comestível está aliado ao resultado da demando do consumidor por alimentos de alta qualidade e pelo aumento da preocupação ambiental no descarte de materiais de embalagens de alimentos não renováveis.
Entre as novas tecnologias de embalagem estão os filmes e revestimentos comestíveis. Os filmes são películas finas previamente formadas e só então aplicadas no produto, como envoltório ou entre as camadas do mesmo. Enquanto que, os revestimentos são filmes formados no produto, cuja base é aplicada diretamente sobre a superfície do mesmo, onde ocorre a secagem e, assim, a formação do filme, com a função de proteger o alimento, permanecendo durante o uso e até durante o consumo (KROCHTA, 2002).

Entre os materiais usados para produção de filmes e revestimentos biodegradáveis, incluem: os polissacarídeos, lipídeos, proteínas e interações entre eles (PARRA, 2004; SEYDIM; SARIKU, 2006; GOUNGA et al., 2007; EMIROĞLU, et al., 2010; SOAZO et al., 2011; ABDOLLAHI et al., 2012;). Essas interações específicas resultam em sistemas com propriedades funcionais melhoradas como: redução da permeabilidade de oxigênio, baixa solubilidade e alta transparência (GOUNGA et al, 2007; HARCEG et al., 2007; GOUNGA et al., 2007).

Diversos autores desenvolveram filme e revestimentos a base de proteína do soro de leite (OUSSALAH et al 2004; PEREZ-GAGO et al., 2006; GOUNGA et al., 2007; YOSHIDA; ANTUNES, 2009; ZINOVIADOU et al., 2009, ATARES et al., 2010; DI PIERRO et al., 2011; RAMOS et al., 2013).

Materiais para embalagens à base de proteína de soro de leite apresentam diversas características que favorecem a sua aplicação, tais como: transparência, (KIM; USTUNOL, 2001), flexibilidade (OSÉS et al., 2009), brilho (LEE et al., 2008) e ausência de odor, o que favorece sua aceitabilidade para consumo (KIM; USTUNOL, 2001). Além disso, apresentam boa propriedade de barreira ao oxigênio, (PEREZ-GAGO et al, 2005) e boas propriedades mecânicas (LEE et al., 2008). No entanto, devido a sua natureza hidrofílica, essas embalagens são altamente permeáveis à água, o que limita a sua aplicação em produtos que requerem barreira à umidade. 
Filmes e revestimentos à base de proteína do soro têm excelente capacidade para incorporar uma grande variedade de aditivos como: dióxido de titânio, polietileno e polipropileno, carboidratos, polissacarídeos, óleos essenciais, lipídeos, caseinato de sódio e outras proteínas (LONGARES et al., 2005; HONG; KROCHTA, 2006; HERCEG et al., 2007; FERREIRA et al., 2007; GHANBARZADEH; OROMIEHI, 2008; ZINIVADAOU et al., 2009; DI PIERRO, 2011; LI et al., 2011), que auxiliam na melhoria das propriedades da embalagem, mantenimento da qualidade e prolongamento da validade comercial do alimento.

Alguns ingredientes incorporados à matriz dos filmes e revestimento como os responsáveis por funções como antimicrobianas, antioxidantes e aromáticas, tornam essas embalagens com propriedades ativas (PEREZ GAGO et al., 2006; SEYDIM; SARIKU, 2006; LEE et al., 2008, OZEDEMIR; FLOROS, 2008).

As diferentes composições do IPS e do CPS podem influenciar acentuadamente nas propriedades de barreira mecânica e propriedades térmicas dos filmes e revestimentos (HONG; KROCHTA, 2006; KOKOSZKA, 2010). A espessura do filme, a permeabilidade ao oxigênio e a umidade também são influenciados por diferentes concentrações de proteína (GOUNGA et al., 2007).

Embalagens proteicas podem ser aplicadas em uma variedade de alimentos, como: frutas in natura, frutas e verduras minimamente processados, queijos e carnes (PEREZ-GAGO et al., 2003; OUSSALAH et al., 2004; SOAZO et al., 2005; YOSHIDA; ANTUNES, 2009; ZINOVIADAU et al., 2009; PINTADO et al., 2010; DI PIERRO 2011). Alimentos congelados, também são favorecidos, devido à resistência dessas embalagens ao processo de congelamento, mantendo sua integridade física (SOAZO et al., 2011).

Javanmard (2008) acondicionou grãos de amendoim secos em embalagem (filme) composta da mistura de CPS e óleo de oliva. O produto foi mantido a $25{ }^{\circ} \mathrm{C}$ por 4 semanas e observou-se baixa absorção de umidade e retardo na rancidez resultando, consequentemente, no aumento da validade comercial do produto quando comparado ao controle (sem embalagem).

Yoshida e Antunes (2009) avaliaram a eficiência da aplicação de filmes à base de proteínas de soro de leite como fechamento superior (tampa) de uma embalagem plástica para armazenamento de pedaços de maçã à temperatura ambiente $\left(25^{\circ} \mathrm{C}\right)$ e sob refrigeração $\left(10^{\circ} \mathrm{C}\right)$. As embalagens com os filmes apresentaram uma barreira moderada à umidade, e a gases e consequentemente aumentaram o tempo de armazenamento da maçã quando comparados ao armazenamento aberto (sem tampa).

Zinoviadou et al. (2009) não observaram diferença no desenvolvimento microbiano de Pseudomonas spp. e bactérias ácido láticas entre a amostra de carne bovina in natura envolvida com IPS e a amostra controle (não envolvida com o filme proteico) estocada a $5{ }^{\circ} \mathrm{C}$. O resultado comprovou que o IPS não serviu como meio de crescimento bacteriano.

Amaral (2014) aplicou CPS como revestimento para conservação de maçã minimamente processada armazenada a $10^{\circ} \mathrm{C}$. Foi observado, que a maçã revestida apresentou melhor coloração (pouco escurecimento) depois de 7 dias de armazenamento e menor contagem de fungos filamentosos e leveduras após 3 dias de armazenamento, em relação a amostra controle (sem revestimento).

O aproveitamento do resíduo da agroindústria, o soro de leite, traz vantagens como: minimiza impactos ambientais e agrega valor a produtos alimentícios, devido às proteínas presente neste soro. Diversos trabalhos estão sendo publicados acerca dos benefícios dessas proteínas para saúde, sua contribuição nutricional e propriedades funcionais. Para realçar as propriedades, e obter um produto com maior teor de proteína, o soro de leite é concentrado ou isolado, o que encarece o comércio das proteínas e consequentemente o produto final. No entanto, as perspectivas para uso dos concentrados proteicos e isolados proteicos na elaboração de alimentos são crescentes.

As embalagens a base de proteína do soro de leite apresentam diversas vantagens como melhorias de qualidade nutricional e garantia de segurança do alimento, além do fato de poderem ser comestíveis e biodegradáveis. Dessa forma, elas atendem o apelo dos consumidores, cada vez mais exigentes, por produtos seguros e de qualidade sem agredir ao meio ambiente.

Faz- se necessários maiores estudos para se atingir uma produção em grande escala a fim de que variedades de produtos sejam lançados no mercado.

\section{CONSIDERAÇÕES FINAIS}

O soro de leite e suas proteínas, que outrora eram descartados das indústrias de laticínio ou subutilizados, têm sofrido uma grande valorização com uma série de descobertas a cerca das suas propriedades funcionais, processos tecnológicos de preparo e hidrólise das proteínas, tendo crescentes pesquisas relacionadas. Agora, um dos desafios, é levar a população o conhecimento das vantagens da incorporação desses produtos à alimentação.

Esses produtos têm um grande potencial de utilização na indústria alimentícia. O soro de leite por apresentar uma rica e comprovada composição nutricional relacionada às suas proteínas: $\alpha$ - lactalbumina, $\beta$ - lactoglobulina, lactoferrina, lactoperoxidases e lisozima, que apresentam um excelente perfil de aminoácidos e são responsáveis por diversos benefícios à saúde, podendo ser usados na elaboração de produtos alimentícios como bolos, biscoitos, sorvetes, pães, bebidas lácteas, entre outros e até mesmo no desenvolvimento de filmes e revestimentos comestíveis para embalar alimentos.

Dessa forma há uma contribuição na melhoria da segurança alimentar, com produtos alimentícios nutricionalmente melhores, e no meio ambiente, com o reaproveitamento de resíduos e produção de embalagens biodegradáveis.

\section{REFERÊNCIAS BIBLIOGRÁFICAS}

ABDOLLAHI, M.; REZAEI, M.; FARZI, G. A novel active bionanocomposite film incorporating rosemary essential oil and nanoclay into chitosan. Journal of Food Engineering, v. 111, p. 343-350, 2012.

ALMEIDA, K.E.; BONASSI, I. A.; ROÇA, R. O. Características físicas e químicas de bebidas lácteas fermentadas e preparadas com soro de queijo minas 
frescal. Ciências Tecnologia de Alimentos, v. 21, n. 2, p. 187-192, 2001.

AMARAL, D.P. Revestimento ativo antiescurecimento à base de proteína do soro de leite aplicado em maçãs minimamente processados. Seropédica: Universidade Federal Rural do Rio de Janeiro, Seropédica, 2014. 73 p. Dissertação Mestrado.

ANDRADE, R.L.P.; MARTINS, J.F.P. Influência da adição da fécula de batata-doce (Ipomoea batatas L.) sobre a viscosidade do permeado de soro de queijo. Ciências e Tecnologia de Alimentos, v.22, n.3, p. 249-253, 2002.

ARTIMONTE, A.P. Avaliação da atividade antimicrobiana da lactoferrina bovina e sua aplicação em filmes protéicos a base de soro de leite. Londrina: Centro de Ciências Biológicas e da Saúde, Universidade Norte do Paraná, Londrina, 2009. 62p. Dissertação Mestrado.

BARBOSA, A.S; ARAÚJO A. S.; FLORÊNCIO, I. M.; BEZERRA, R. R. A.; FLORENTINO, E. R. Estudo cinético da fermentação do soro de queijo de coalho para produção de aguardente. Revista Verde de Agroecologia e Desenvolvimento Sustentável, v. 5, n. 3, p. 237-254, 2010 .

BOUTIN, C; GIROUX, H. J.; PAQUIN, P.; BRITTEN, M. Characterization and acid-induced gelation of butter oil emulsions produced from heated whey protein dispersions. International Dairy Journal, v.17, p. 696703, 2007.

BRASIL Decreto $\mathrm{n}^{\circ}$ 1.812, 08/02/1996. Regulamento da Inspeção Industrial e Sanitária de Produtos de Origem Animal. 08 de fevereiro de 1996

BRASIL MAPA. Portaria $n^{\circ}$ 53, 10/4/13. Regulamento Técnico de Identidade e Qualidade de Soro de Leite. D.O.U., 11/04/2013, S.1. C.P. encerrada 10/05/2013.

CALDEIRA, L.A.; FERRÃO, S.P.B.; FERNANDES, S. A. A; MAGNAVITA, A. P. A.; SANTOS, T. D. R. Desenvolvimento de bebida láctea sabor morango utilizando diferentes níveis de iogurte e soro lácteo obtidos com leite de búfala. Ciências Rural, v. 40, n.10, 2010 .

CIABOTTI, S.; BARCELOS, M. F. P.; CIRILlO, M. A.; PINHEIRO, A. C. M. Propriedades tecnológicas e sensoriais de produto similar ao tofu obtido pela adição de soro de leite ao extrato de soja. Ciência e Tecnologia de Alimentos, v. 29, n. 2, p. 346-353, 2009.

DI PIERRO, P. Chitosan/whey protein film as active coating to extend ricotta shelf-life. Food Science and Technology, v. 44, p. 2324-2327, 2011.

DINIZ, D.M.; DRUZIAN, J.I.; AUDIBERT, S. Produção de Goma Xantana por Cepas Nativas de Xanthomonas campestris a partir de casca de cacau ou soro de Leite. Polímeros, v.22, n. 3, p. 278-281, 2012.
EGITO, A. S; BENEVIDES, S. D.; LAGUNA, L. E.; SANTOS, K.O. O. Processamento de ricota a partir do soro de queijo de cabra. Embrapa-Comunicado Técnico, 82, Sobral, Ceará, 2007. Disponível em: http://www.cnpc.embrapa.br/admin/pdf/003100121520. cot82.pdf. Acesso em: 20 fev. 2014.

EMBRAPA - Empresa Brasileira de Pesquisa Agropecuária. Soro de leite é foco de pesquisa para alimentos funcionais, 2012: Disponível em: http://www.embrapa.br/imprensa/noticias/2012/maio/2asemana/soro-de-leite-e-foco-de-pesquisa-paraalimentos-funcionais/?searchterm=. Acesso em: $20 \mathrm{fev}$. 2014.

EMBRAPA - Empresa Brasileira de Pesquisas Agropecuárias. Embrapa lança produtos extrusados com maior valor nutricional, 2011. Disponível em: http://www.embrapa.br/imprensa/noticias/2011/abril/4asemana/embrapa-lanca-produtos-extrusados-commelhor-valor-nutricional/?searchterm=. Acesso em: 20 fev. 2014.

EMIROĞLU, Z.R.; YEMIŞ, G. P.; COŞKUN, B. K.; CANDOĞAN, K. Antimicrobial activity of soy edible films incorporated with thyme and oregano essential oils on fresh ground beef patties. Meat Science, v. 86, p. 283-288, 2010.

FERREIRA, C.O.; NUNES, C. A.; DELGADILLO, I.; LOPES-DA-SILVA, J. A. Characterization of chitosanwhey protein films at acid $\mathrm{pH}$. Food Research International, v. 42, p. 807-813, 2009.

GHANBARZADEH, B.; OROMIEHI, A.R. Biodegradable biocomposite films based on whey protein and zein: Barrier, mechanical properties and AFM analysis. International Journal of Biological Macromolecules, v. 43, p. 209-215, 2008.

GOUNGA, M.E.; XU, S-Y.; WANG, Z. Whey protein isolate-based edible films as affected by protein concentration, glycerol ratio and pullulan addition in film formation. Journal of Food Engineering, v. 83, p. 521-530, 2007.

GUIMARÃES, D.H. Utilização de soro de queijo na elaboração de biscoitos doces. RECEN, v. 13, n. 2, p. 271-285, 2011.

HARAGUCHI, F.K.; ABREU, W.C.; PAULA, H. Proteínas do soro do leite: composição, propriedades nutricionais, aplicações no esporte e benefícios para a saúde humana Revista da Nutrição, v. 19, n. 4, p. 479-488, 2006.

HERCEG, Z.; REŽEK, A.; LELAS, V.; KREŠIĆ, G.; FRANETOVIĆ, M. Effect of carbohydrates on the emulsifying, foaming and freezing properties of whey protein suspensions. Journal of Food Engineering, v. 79, p. 279-286, 2007.

HERNANDEZ-IZQUIERDO, V.M.; KROCHTA, J.M. Thermoplastic processing of proteins for film formation 
e a review. Journal of Food Science, v. 73, n. 2, p. 30$39,2008$.

HONG, S-I.; KROCHTA, J.M. Oxygen barrier performance of whey-protein-coated plastic films as affected by temperature, relative humidity, base film and protein type. Journal of Food Engineering, v. 77, p. 739-745, 2006.

IBGE -Instituto Brasileiro de Geografia e estatística. Disponível em: <ftp://ftp.ibge.gov.br/Producao_Pecuaria/Producao_da_ Pecuaria_Municipal/2011/tabelas_pdf/tab02.pdf> Acesso em: 24 de mai. 2014.

JAVANMARD, M. Effect of whey protein edible film packaging on the quality and moisture uptake of dried peanuts. Journal of Food Process Engineering, v. 31, p. 503-516, 2008.

KIM, S-J, USTUNOL, Z. Sensory attributes of whey protein isolate and candelilla wax emulsion edible films. Journal of food science, v. 66, n. 6, p. 909-911, 2001.

KOKOSZKA, S. Water vapour permeability, thermal and wetting properties of whey protein isolate based edible films. International Dairy Journal, v. 20, p. 53-60, 2010.

KROCHTA, J. M. Proteins as raw materials for films and coatings: definitions, current status, and opportunities. In: GENNADIOS, A. Protein-based films and coatings. Boca Raton: CRC Press LLC, 2002, cap. 1, p. 21-61.

LEE, J-W.; SON, S-M.; HONG, S-I. Characterization of protein-coated polypropylene films as a novel composite structure for active food packaging application. Journal of Food Engineering, v. 86, p. 484-493, 2008.

LI, Y.; JIANG, Y.; LIU, F.; REN, F.; ZHAO, G.; LENG, X. Fabrication and characterization of $\mathrm{TiO}_{2} /$ whey protein isolate nanocomposite film. Food Hydrocolloids, v. 25, p. 1098-1104, 2011.

LONGARES, A.; MONAHAN, F. J.; O'RIORDAN, E.D. O'SULLIVAN, M. Physical properties of edible films made from mixtures of sodium caseinate and WPI. International Dairy Journal, v. 15, p. 1255-1260, 2005.

MADUREIRA, A.R.; PEREIRA, C. I.; GOMES, A. M. P.; PINTADO, M.E.; MALCATA, F. X. Bovine whey proteins-Overview on their main biological properties. Food Research. International, v. 40, p. 1197-1211, 2007.

MAGANHA, M.F.B. Guia técnico ambiental da indústria de produtos lácteos. São Paulo: CETESB, 2006. Disponivel em: http://www.cetesb.sp.gov.br. Acesso em: 15 fev. 2014.

MARSHALL, K. Therapeutic applications of whey protein. AMR, v. 9, n. 2, p.136- 156, 2004.
NGARIZE, S.; ADAMS, A.; HOWELL, N. A comparative study of heat and high pressure induced gels of whey and egg albumen proteins and their binary mixtures. Food Hydrocolloids, v. 19, n. 984-996, 2005.

OMS -. Organização Mundial de Saúde. Código de prácticas de higiene para la leche y los productos lácteos: producción de alimentos de origen animal - CAC/RCP 57-2004. 2a ed. Roma: FAO/OMS, 2009.

OSÉS, J.; FERNAÁNDEZ-PAN, I.; MENDOZA, M.; MATÉ, J. A. Stability of the mechanical properties of edible films based on whey protein isolate during storage at different relative humidity. Food Hydrocolloids, v. 23, p. 125-131, 2009.

OUSSALAH, M.; CAILLET, S.; SALMIÉARI, S.; SAUCIER, L.; LACROIX, M. Antimicrobial and Antioxidant Effects of Milk Protein-Based Film Containing Essential Oils for the Preservation of Whole Beef Muscle. Journal of Agricultural and Food Chemistry, v. 52, n. 18, p. 5598-5605, 2004.

OZDEMIR, M.; FLOROS, J.D. Optimization of edible whey protein films containing preservatives for water vapor permeability, water solubility and sensory characteristics. Journal of Food Engineering, v. 86, p. 215-224, 2008.

PAGNO, C.H.; BALDASSO, C.; TESSARO, I. C.; FLORES, S. H.; JONG, E. V. Obtention of whey protein and characterization of its technological functional properties. Alimentos e Nutrição, v. 20, n. 2, p. 231-239, 2009.

PARRA, D.F. Mechanical properties and water vapor transmission in some blends of cassava starch edible films. Carbohydrate Polymers, v. 58, p. 475-481, 2004.

PELEGRINE， D.H.G.; CARRASQUEIRA， R.L. Aproveitamento do soro do leite no enriquecimento nutricional de bebidas. Brazilian Journal Food Technology, v. 62, n. 6, p. 1004-11, 2008.

PELEGRINE, D.H.G.; GASPARETTO, C.A. Estudo da solubilidade das proteínas presentes no soro de leite e na clara de ovo. Revista Brasileira de Produtos Agroindustriais, v.5, n.1, p.57-65, 2003.

PEREZ-GAGO, M. B.; KROCHTA, J. M. Drying temperature effect on water vapor permeability and mechanical properties of whey protein-lipid emulsion films. Journal Agricultural and Food Chemistry, v. 48, p. 2687-2692, 2000.

PEREZ-GAGO, M.B.; NADAUD, P.; KROCHTA J. M. Water vapor permeability, solubility, and tensile properties of heat-denatured versus native whey protein films. Journal of food science, v. 64, n.6, p. 1034-1037, 1999.

PEREZ-GAGO, M.B.; SERRA, M.; ALONSO, M.; MATEOS, M.; DEL RÍO, M. A. Effect of solid content and lipid content of whey protein isolate-beeswax edible 
coatings on color change of fresh-cut apples. Journal of food science, v. 68, v.7, p. 2186-2191, 2003.

PEREZ-GAGO, M.B.; SERRA, M.; ALONSO, M.; MATEOS, M.; DEL RÍO, M. A. Effect of whey proteinand hydroxypropyl methylcellulose-based edible composite coatings on color change of fresh-cut apples. Postharvest Biology and Tecnology, v. 36, p. 77-85, 2005.

PEREZ-GAGO, M.B.; SERRA, M.; DEL RÍO, M.A. Color change of fresh-cut apples coated with whey protein concentrate-based edible coatings. Postharvest Biology and Tecnology, 39, p.84-92, 2006.

PINTADO, C.M.B.S., FERREIRA, M.A.S.S., SOUSA, I. Control of pathogenic and spoilage microorganisms from cheese surface by whey protein films containing malic acid, nisin and natamycin. Food Control, v. 21, p. 240-246, 2010.

RAMOS, O.; REINAS, I.; SILVA, S.I.; FERNANDES, J. C.; CERQUEIRA, M. A.; PEREIRA, R. N.; VICENTE, A. A; POÇAS, M. F.; PINTADO, M. E.; MALCATA, F. $\mathrm{X}$. Effect of whey protein purity and glycerol content upon physical properties of edible films manufactured therefrom. Food Hydrocolloids, v. 30, p. 110-122, 2013.

ROCHA, L.O.F. Avaliação físico-química e sensorial de doce de leite elaborado com extrato hidrossolúvel de soja e soro de leite sabor café. Revista Brasileira de Produtos Agroindustriais, v. 14, n. 3, p. 251-259, 2012.

ROMAN, J. A.; SGARBIERI, V. C physical-chemical characterization of whey protein isolate and gelatin from bovine origin. Brazilian Journal of Food Technology. v. 10, n. 2, p. 137-143, 2007.

SANTOS, C.T.; MARQUES, G. M. R.; FONTAN G. C. R.; FONTAN, R. C. I.; BONOMO, R. C.F.; BONOMO, P. Elaboração e caracterização de uma bebida láctea fermentada com polpa de umbu (Spondias tuberosa sp.). Revista Brasileira de Produtos Agroindustriais, v. 8, n. 2, p. 111-116, 2006.

SCHMITT, C.; BOVAY, C.; VUILLIOMENET, A-M.; ROUVET, M.; BOVETTO, L. Influence of protein and mineral composition on the formation of whey protein heat-induced microgels. Food Hydrocolloids, v. 25, p. 558-567, 2011.

SEYDIM, A. C.; SARIKU, G. Antimicrobial activity of whey protein based edible films incorporated with oregano, rosemary and garlic essential oils. Food Research International, v. 39, p. 639-644, 2006.

SGARBIERI, V. C. Propriedades fisiológicas-funcionais das proteínas do soro de leite. Revista da Nutrição, v. 17, n. 4, p. 397-409, 2004.
SILVA, K.; BOLINI, H. M. A.; ANTUNES, A. J. Soro de leite bovino em sorvete. Alimentos e Nutrição, v. 15, n. 2, p. 187-196, 2004.

SILVIA, P.A.; ASSIS, G. T.; CARVALHO, A. V.; SIMÕES, M. G. Desenvolvimento e caracterização de cereal matinal extrusado de mandioca enriquecido com concentrado proteico de soro de leite. Brazilian Journal Food Technology, v. 14, n. 4, p. 260-266, 2011.

SINHA, R.; RADHA, C.; PRAKASH, J.; KAUL, P. Whey protein hydrolysate: Functional properties, nutritional quality and utilization in beverage formulation. Food Chemistry, v. 101, p. 1484-1491, 2007.

SIQUEIRA, K.B.; CARNEIRO, A. V.; ALMEIDA, M. F.; SOUZA, R. C. S. N. P. O mercado lácteo brasileiro no contexto mundial. Embrapa-Circular Técnico, 104, Juíz de Fora, Minas Gerais, 2010. Disponível em: http://www.infoteca.cnptia.embrapa.br/bitstream/doc/88 6169/1/CT104Kennya.pdf. Acesso em: 25 mai. 2014.

SOAZO, M. PÉREZ, L. M.; RUBIOLO, A. C.; VERDINI, R. A. Effect of freezing on physical properties of whey protein emulsion films. Food Hydrocolloids, v. 31, p. 256-263, 2013.

SOAZO, M., RUBIOLO, A.C. VERDINI, R.A. Effect of drying temperature and beeswax content on physical properties of whey protein emulsion films. Food Hydrocolloids, v. 25, p. 1251-1255, 2011.

VALDUGA, E.; PAVIN, L. C.; MAZUR S. P.; FINZER, J. R. D. Aplicação do soro de leite em pó na panificação Alimentos e Nutrição, v. 17, n. 4, p. p.393-400, 2006.

VIDIGAL, M.C.T.R.; MINIM, V. P. R.; RAMOS, A. M.; CERESINO, E. B.; DINIZ, M. D. M. S.; CAMILLOTO, G. P.; MINIM, L. A. Effect of whey protein concentrate on texture of fat-free desserts: sensory and instrumental measurements. Ciências e Tecnologia de Alimentos, v. 32, n. 2, p. 412-418, 2012.

YOSHIDA, C.M.P., ANTUNES, A. J. Aplicação de filmes proteicos à base de soro de leite. Ciências e Tecnologia de Alimentos, v. 29, n. 2, p. 420-430, 2009.

ZAMBRANO, F.; SILVA, M. C.; ORMENESE , R. C. C.; YOTSUYANAGI, K. Concentrado proteico de soro como substituto de gordura em pão de queijo. Brazilian Journal Food Technology, v. 15, v. 3, p. 244-252, 2012.

ZAVAREZE, E.R.; MORAES, K. S.; SALAS-MELLADO, M. L. M. Qualidade tecnológica e sensorial de bolos elaborados com soro de leite. Ciências e Tecnologia de Alimentos, v. 30, n. 1, p. 100-105, 2010.

ZINOVIADOU, K.G.; KOUTSOUMANIS, K.P., BILIADERIS, C. G. Physico-chemical properties of whey protein isolate films containing oregano oil and their antimicrobial action against spoilage flora of fresh beef. Meat Science, v. 82, p. 338-345, 2009. 